\title{
25. COMMISSION DE PHOTOMÉTRIE STELLAIRE
}

Président: M. F. H. SeAres, Mount Wilson Observatory, Pasadena, Cal., U.S.A. Membres: MM. Baade, J. Baillaud, A. Bemporad, Bergstrand, Danjon, Graff, Greaves, W. K. Green, Guthnick, Hassenstein, Hellerich, Hertzsprung, Jones, Lindblad, Malmquist, Pannekoek, Mme Payne Gaposchkin, MM. Ross, Rougier, Sampson, Schilt, Shapley, Vanderlinden, van Rhijn, von Zeipel.

The following summarizes the activities of various members of the Commission in matters pertaining to stellar photometry during the interval I932-35:

\section{R. Osservatorio Astrofisico di Catania}

La partie photométrique des trois derniers volumes du Catalogue Astrographique (zone de Catane entre $+46^{\circ}$ et $+55^{\circ}$ ) est soigneusement dressee sur le système de Miss Leavitt (Harv. Annals, 8r).

L'erreur moyenne des grandeurs, d'après la réduction de roo plaques (zones $+5^{\circ} \mathrm{a}+54^{\circ}$, entre $6^{\mathrm{h}}$ et $12^{\mathrm{h}}$ ), $\mathrm{n}^{\prime}$ est que de $\pm 0^{\mathrm{m}} \cdot 08$. Nos réductions photométriques ont été effectuées par la formule

$$
D=a-b g+c g^{2}-d g^{3},
$$

où $D$ dénote le diamètre de l'image photographique et $G=8^{\mathrm{m}}+g$ dénote la grandeur de l'étoile.

$D^{\prime}$ après les réductions de 72 plaques des zones $+47^{\circ}$ et $+48^{\circ}$ entre $12^{\mathrm{h}}$ et $18^{\mathrm{h}}$ on obtient (en ordonnant par les valeurs croissantes du coefficient $c$ ) les formules et les grandeurs moyennes qui suivent:

(I) $D=29 \cdot 67-5 \cdot 94 g+0 \cdot 34 g^{2}-0 \cdot 11 g^{3}$

(II) $D=28 \cdot 88-7 \cdot 24 g+0 \cdot 98 g^{2}-0 \cdot 20 g^{3}$
(III) $D=30 \cdot 73-10 \cdot 15 g+2 \cdot 71 g^{2}-0 \cdot 47 g^{3}$

\begin{tabular}{crrr} 
& \multicolumn{3}{c}{ Grandeur } \\
\cline { 2 - 4 } Diam. & \multicolumn{1}{c}{ I } & \multicolumn{1}{c}{ II } & \multicolumn{1}{c}{ III } \\
5 & $\mathbf{1 1 . 9 2}$ & $\mathbf{1 1 . 7 5}$ & $\mathbf{1 1 . 8 5}$ \\
10 & $\mathbf{1 1 . 2 8}$ & $\mathbf{1 1 . 0 8}$ & $\mathbf{1 1 . 2 8}$ \\
$\mathbf{1 5}$ & $\mathbf{1 0 . 5 4}$ & $\mathbf{1 0 . 3 0}$ & $\mathbf{1 0 . 4 9}$ \\
$\mathbf{2 0}$ & $\mathbf{9 . 7 0}$ & $\mathbf{9 . 4 2}$ & $\mathbf{9 . 5 0}$ \\
$\mathbf{2 5}$ & $\mathbf{8 . 8 2}$ & $\mathbf{8 . 5 8}$ & $\mathbf{8 . 6 7}$ \\
$\mathbf{3 0}$ & $\mathbf{7 . 9 4}$ & $\mathbf{7 . 8 5}$ & $\mathbf{8 . 0 7}$ \\
$\mathbf{3 5}$ & $\mathbf{7 . 1 6}$ & $\mathbf{7 . 2 5}$ & $\mathbf{7 . 6 2}$ \\
$\mathbf{4 0}$ & $\mathbf{6 . 4 6}$ & $\mathbf{6 . 7 4}$ & $\mathbf{7 . 2 5}$ \\
$\mathbf{4 5}$ & $\mathbf{5 . 8 5}$ & $\mathbf{6 . 3 0}$ & $\mathbf{6 . 7 4}$ \\
$\mathbf{5 0}$ & $\mathbf{5 . 3 4}$ & $\mathbf{5 . 9 2}$ & $\mathbf{6 . 6 8}$
\end{tabular}

A. BEMPORAD

\section{UPSALA OBSERVATORY}

Photométrie des étoiles de la zone de déclinaison comprise entre $+60^{\circ}$ et $+65^{\circ}$ (Meddelanden frä Astronomiska Observatorium Upsala No. 57, I933). La zone a été doublement couverte par 72 clichés, dont les centres sont situés sur le cercle de $+62^{\circ} 30^{\prime}$ de déclinaison et dans les ascensions droites $0^{\mathrm{h}} \mathrm{O}^{\mathrm{m}}, \mathrm{o}^{\mathrm{h}} 2 \mathrm{O}^{\mathrm{m}}, \mathrm{o}^{\mathrm{h}} 4 \mathrm{O}^{\mathrm{m}}$, etc. Le centre de chaque cliché est situé sur les bords des deux clichés voisins. Pour le rattachement à la zone de Greenwich $+65^{\circ} \mathrm{a}+75^{\circ}$, une série spéciale de $\mathrm{I} 2$ clichés a été prise. Les centres de ces clichés sont situés sur le cercle de $+65^{\circ}$ de déclinaison et dans les ascensions droites $0^{\mathrm{h}} \mathrm{O}^{\mathrm{m}}, 2^{\mathrm{h}} \mathrm{O}^{\mathrm{m}}, 4^{\mathrm{h}} \mathrm{O}^{\mathrm{m}}$, etc. La moitié méridionale d'un tel cliché appartient à notre zone, la moitié du nord à celle de Greenwich. Ainsi le programme complet embrasse 84 clichés distribués symétriquement tout autour du Ciel. 
L'instrument disposé est un équatorial-astrographe de Zeiss, muni d'un objectif "Triplet" de $200 \mathrm{~mm}$. de diamètre et de $995 \mathrm{~mm}$. de distance focale. L'ouverture libre de l'objectif a été réduite à $100 \mathrm{~mm}$. Les plaques employées sont de la marque "Ilford Special Rapid" de taille I $60 \times \mathrm{x} 60 \mathrm{~mm}$., fabriquées en verre plan, dit "patent plate." La partie centrale du cliché, occupant $5^{\circ}$ en déclinaison et $40^{\mathrm{m}}$ en ascension droite seulement a été mesurée.

Pour la détermination de l'échelle des magnitudes l'instrument a été muni d'un réseau-objectif. La constante de ce réseau, c.-à-d. la différence entre les magnitudes des images centrales et diffractées, est de $0^{\mathrm{m} \cdot} \cdot 788$.

Les poses ont toujours été faites dans le foyer de l'objectif. Chaque cliché contient deux poses de $10^{m}$, et les deux images ont toujours été mesurées.

La réduction au centre du cliché-tout insignifiante d'ailleurs-a été faite pour toutes les mesures. Comme tous les clichés ont été pris près du zénith, l'influence de l'extinction atmosphérique différentielle a été tout à fait négligeable.

Les mesures ont été effectuées au moyen d'un microphotomètre Schilt. L'échelle ayant été déterminée pour chaque cliché, on les a rattaché l'un à l'autre dans un système commun, dont le zéro, arbitrairement choisi, a finalement été rectifié au moyen d'une correction constante pour tout l'ensemble des clichés. Pour la détermination de cette correction on a mesuré, sur les I2 clichés de la série spéciale, en tout 293 étoiles de notre zone et 286 étoiles de celle de Greenwich. Les magnitudes de ces dernières étoiles avaient été transformées dans le Système International des magnitudes au moyen des corrections de Harvard Annals, 7r, combinées à celles de Harvard Bull. No. 78I.

Le catalogue embrasse toutes les étoiles de la zone $+60^{\circ} \mathrm{a}+65^{\circ}$, pour lesquelles la magnitude visuelle est indiquée dans la $B \cdot D$. $\leqq 9^{\mathrm{m}} \cdot 0$. Le nombre total des étoiles cataloguées est de 4616. Pour les magnitudes du catalogue on a calculé en moyenne l'erreur probable de $\pm 0^{\mathrm{m} \cdot} \cdot 028$.

Dans une mémoire spéciale Étude sur les relations existant entre les divers systèmes de grandeurs stellaires photographiques (Upsala Meddelanden, No. 59, I934) j'ai établi des comparaisons détaillées entre le catalogue d'Upsala d'une part et la Yerkes Actinometry, 2 (Fairley), le Catalogue de Poulkovo (Lehmann-Balanowskaja), le Catalogue de Greenwich $+65^{\circ}$ à $+75^{\circ}$ et la Harvard Photographic Photometry de l'autre.

En ce qui concerne le catalogue de Greenwich il a été établi que les équations d'échelle et de couleur ne sont pas indépendantes l'une de l'autre. En effetl'équation de couleur croît avec l'éclat des étoiles.

L'équation d'échelle et l'équation spectrale (ou de couleur) entre les divers catalogues peuvent être déterminées avec une sûreté remarquable. Quant à la dernière équation, les résultats nous révèlent que les systèmes optiques d'Upsala et de Yerkes présentent entre eux une ressemblance caractéristique, tandis que ceux de Pulkovo et de Harvard, très voisins l'un de l'autre, diffèrent décidément des deux premiers.

Les différences des zéros des divers catalogues, fonctions de l'ascension droite et probablement aussi de la déclinaison, sont plus difficiles à déterminer d'une manière satisfaisante. Il semble qu'en général la fixation exacte d'un zéro indépendant des positions des étoiles est sujette à des difficultés considérables. C'est là peut-être un des points les plus faibles de la photométrie photographique des étoiles. 


\section{Amherst College Observatory}

We are working on a systematic programme observing the photographic magnitudes of a group of twenty asteroids. Since we have to determine the comparison magnitudes for each set of observations on each object, an important by-product of the work will be a catalogue of photographic magnitudes of the comparison stars. This catalogue will include stars from the fifth to the twelfth photographic magnitude, mostly within $10^{\circ}$ of the ecliptic. The plates are taken with a Ross-Lundin lens of $4 \cdot 5$-inch aperture and are measured on a thermo-electric photometer. Each field is compared at least four times with the Polar Sequence, the scale being determined from the I.A.U. values. Since we are also superimposing the different fields, we shall eventually have all of the star magnitudes and also the asteroid magnitudes, reduced to a scale as nearly as possible that of the I.A.U. and also internally homogeneous.

We hope to publish a preliminary discussion of our methods and results for a few asteroids within the coming year. It is difficult for me to say when the first star list will be published for I shall wait until I have at least 750 stars well distributed through the zone.

In our particular problem it is possible for us to remain within $3^{\circ}$ of the centre of the plate by frequently shifting the centre to compensate for the motion of the asteroid. In some cases, however, we have to go farther afield in search of suitable comparison stars, particularly when the asteroid is bright.

WARREN K. GREEN

\section{UNIVERSITÄTS-STERNWARTE BERLIN-BABELSBERG}

An der Sternwarte Berlin-Babelsberg ist seit drei Jahren ein fundamentales photometrisches Programm im Gang, für das die Beobachtungen jetzt vor dem Abschluss stehen. Dr M. Güssow hat für dieses Programm mit einem lichtelektrischen Sternphotometer am 3I-cm. Refraktor die Helligkeiten und Farbenindices zunächst von 98 ausgewählten Sternen mit Blaufilter, ohne Filter, und mit Gelbfilter gemessen. Zur Bestimmung der effektiven Spektralbereiche sollen Objektiv und Zelle im Laboratorium mit einem Doppelmonochromator untersucht werden, der jetzt betriebsfertig geworden ist. Die bei diesem Teilprogramm gesammelten Erfahrungen sollen dann für ein grösseres Programm fundamentaler Helligkeiten benutzt werden.

\section{P. GuTHNICK}

\section{Astrophysikalisches Observatorium, Potsdam}

Dr W. Becker begann mit der Ausmessung der direkten Aufnahmen der südlichen Kapteyn-Felder an einem lichtelektrischen Plattenphotometer zwecks Ableitung der photographischen Grössen. Die Platten waren in den Jahren I928-29 auf der deutschen La Paz-Station aufgenommen und enthalten die Sterne hellere als $13^{\mathrm{m}}$.

Der Unterzeichnete legte die Fortschritte in den Methoden der visuellen Astrophotometrie während der Jahre I930-34 in einem Artikel dar, welcher eine Ergänzung bildet zu Bd. II, Kap. 6 ("Visuelle Photometrie") des von G. Eberhard, A. Kohlschütter und H. Ludendorff herausgegebenen Handbuch der Astrophysik. Der die sämtlichen Nachträge enthaltende Ergänzungsband zu diesem Handbuch wird voraussichtlich Ende I935 im Druck erscheinen.

W. HASSENSTEIN 


\section{Royal ObSeRVATORY, GREenWICH}

No photometric work on stellar magnitudes has been undertaken at Greenwich since the last meeting of the Union.

Whilst at the Cape Observatory I had formulated plans for a programme of extrafocal photometry, using lenses of 5-inches aperture, 35-inches focus, of type generally similar to the lens designed by F. E. Ross. The intention was to mount two lenses of the same focal length, one photographic and one photovisual, on the same mounting for the derivation of photographic and photovisual magnitudes of the same stars.

A Schilt microphotometer was purchased for the measurement of the plates; the details of the design of the lenses had been decided upon and the photographic lens had been ordered before I left the Cape. The lens was not completed and delivered until after I left.

It is Dr Jackson's intention to carry on this programme, which seemed to me particularly suitable to the conditions at the Cape, where there is a large amount of clear sky but a low standard of average definition.

H. SPENCER JONES

\section{STOCKHOLM OBSERVATORY}

My present work is a continuation of the photometric investigation near the north galactic pole, published in Lund Medd. Ser. II, No. 37 (Trans. I.A.U. 3, I49, I52, I928), and embraces determinations of photographic magnitudes for the stars between RA $12^{\mathrm{b}}-13^{\mathrm{h}}$, Decl. $+29^{\circ}-+38^{\circ}$. The chief instrument is the $40-\mathrm{cm}$. astrograph $(f 200 \mathrm{~cm}$.) with which the following series of plates have been taken. The plates have been measured with a Schilt thermoelectric photometer.

(I) Nine plates $(18 \times 24 \mathrm{~cm}$.) with plate centres at:

$\begin{array}{cccc} & 12^{\mathrm{h}} 12^{\mathrm{m}} 50^{\mathrm{s}} & 12^{\mathrm{h}} 28^{\mathrm{m}} 10^{\mathrm{s}} & 12^{\mathrm{h}} 43^{\mathrm{m}} 30^{\mathrm{s}} \\ +36^{\circ} 50^{\prime} & 1 & 2 & 3 \\ +33^{\circ} 30^{\prime} & 4 & 5 & 6 \\ +30^{\circ} 10^{\prime} & 7 & 8 & 9\end{array}$

Exposures with two circular diaphragms of 20 and $10 \mathrm{~cm}$. diameters have been used. With the $20-\mathrm{cm}$. diaphragm three exposures of $6^{\mathrm{m}}, 2^{\mathrm{m}}$, and $40^{\mathrm{s}}$ were made on each plate; with the Io $\mathrm{cm}$. diaphragm, two exposures of $2^{\mathrm{m}}$ and of $40^{\mathrm{s}}$. Further, the Polar Sequence was photographed with the same diaphragms and exposure-times on each plate. This series gives the photographic magnitudes for the stars $7^{\mathrm{m}}-13^{\mathrm{m}}$.

(2) Two plates $(18 \times 24 \mathrm{~cm}$.), with centres coinciding with the central region 5 above; on each two exposures, $12^{\mathrm{m}}, 6^{\mathrm{m}}$, without diaphragm, also two exposures on the Polar Sequence. This series gives photographic magnitudes for stars between II ${ }^{\mathrm{m}}-\mathrm{I}^{\mathrm{m}}$.

(3) Four plates $(18 \times 24 \mathrm{~cm}$.) with the following plate-centres:

$\begin{array}{ccc} & 12^{\mathrm{h}} 19^{\mathrm{m}} 10^{\mathrm{s}} & 12^{\mathrm{h}} 37^{\mathrm{m}} 10^{\mathrm{s}} \\ +36^{\circ} 0^{\prime} & 1 & 2 \\ +31^{\circ} 0^{\prime} & 3 & 4\end{array}$

These plates received a single exposure of $I^{\mathrm{h}}$, without diaphragm, but with a wiregrating placed in front of the objective. The scale is determined in the usual way from a comparison of the central images and the first-order spectra; the zero-point, through comparison with the preceding series. Magnitudes, $10^{\mathrm{m}} \cdot 5^{-15^{\mathrm{m}}}$. 
A fourth series of nine plates $(\mathrm{I} 3 \times \mathrm{I} 8 \mathrm{~cm}$.), with plate centres coinciding with those of series I, has been obtained with the Triplet $\mathrm{K}(30 / \mathrm{I} 50 \mathrm{~cm}$.) of the Lippert astrograph in Hamburg-Bergedorf; exposure, $30^{\mathrm{m}}$ on each plate. The zero-points and scales of these plates are obtained from comparisons with the previous series. Magnitudes $\mathrm{I} 2^{\mathrm{m}}-\mathrm{I}^{\mathrm{m}} \cdot \mathbf{5}$.

Colour-indices of the stars have been determined with the reflector at HamburgBergedorf in the manner described in Lund Medd. Ser. II, No. 37.

With the same centres as for series I, short spectra of the stars considered were obtained with the astrograph in Saltsjöbaden combined with an objective-prism with a refracting angle of $4^{\circ} \cdot 8$ for spectral classification and for the separation of the giants and dwarfs of the later types. These spectra have now been registered with the Koch-Goos photo-electric microphotometer of the Observatory.

K. G. Malmouist

\section{Columbia University Department of Astronomy}

The systematic programme of photographic magnitudes with the 3-inch Ross Lens for the AG stars was started at the Yale Observatory in I928. It has been continued at Columbia since I93r.

Magnitudes for the zones between $+25^{\circ}$ and $+30^{\circ}$ and between $+20^{\circ}$ and $+25^{\circ}$ have been published in the Transactions of the Astronomical Observatory of Yale University, 9, 10. A description of the method is given in the introduction to vol. 9.

We are at present measuring the magnitudes for the two zones from $+50^{\circ}$ to $+60^{\circ}$. All the plates have been secured at the Yale Observatory through the kind co-operation of Dr Schlesinger. The measurements are well advanced and will be ready for publication at an early date. They will be strictly referred to the zero point of the North Polar Sequence, since each plate has an exposure on the pole.

This programme will be extended by the observation of the magnitudes in the four zones of $5^{\circ}$ each between $+30^{\circ}$ and $+50^{\circ}$. The Yale Observatory has already secured about one-half of the 400 plates required to cover these zones. We are not going north of $+60^{\circ}$, since the magnitudes are known already through the work of the Greenwich $\left(+65^{\circ}\right.$ to $\left.+90^{\circ}\right)$ and Upsala $\left(+60^{\circ}\right.$ to $+65^{\circ}$, Meddelanden Upsala, No. 57) observatories.

JAN SchILT

\section{HaRvard College ObSeRvatory}

I. Photographic Magnitudes of Bright Stars. Programme, all photographic magnitudes brighter than $8^{\mathrm{m}} \cdot 25$, covering the sky in successive strips, $10^{\circ}$ wide in declination. Completed and circulated in the form of mimeographed sheets, from $+90^{\circ}$ to $+57^{\circ} \cdot 5$. Completed and ready to be circulated in the same form as the polar cap, from $+25^{\circ}$ to $+15^{\circ}$. This second section furnishes the standards for the southern sky. In process of measurement and reduction, from $-55^{\circ}$ to $-65^{\circ}$. This section should be completely reduced by the time the Union meets. The southern polar cap is next to be covered, and, lastly, the southern sky from $-55^{\circ}$ to $+15^{\circ}$. The plates for the programme are almost all taken. Details of measurement and reduction have been given in Harvard Bulletin, No. 892, I933. It is believed, both from direct comparisons and from our knowledge of the colour coefficients of the twin Ross lenses used for the work, that the magnitudes of the catalogue are on the International System. Measurements by routine assistants; reductions by Mrs Gaposchkin. 
2. Photovisual System, reductions of Visual Magnitudes of all Stars in the Harvard and Potsdam Photometries. A uniform catalogue, based on the corrections derived in Harvard Annals, 89, Nos. I and 3. In manuscript and more than two-thirds completed. Reductions carried out by a student assistant.

3. Photovisual Standards for Series VIII of the Atlas Stellarum Variabilium. Magnitudes of about r920 stars in 42 sequences, based directly on the North Polar Sequence, and apparently on the International System. See Harvard Bulletin, No. 892 , p. 22. The magnitudes are to be published by the Vatican Observatory. Measurement and reductions by Miss Frances Wright.

4. Photographic Standards for the Henry Draper Extension, I. A series of fifty-four photographic sequences in and near Taurus, based on the North Polar Sequence by means of plates taken with the 8-inch Draper telescope; the divergence from the International System is small, since the colour coefficient of the 8-inch Draper telescope is small. Published as No. 4 of vol. 89 of the Harvard Annals. Measurement and reductions by Miss Frances Wright and Mrs Gaposchkin.

5. Photographic Standards for the Henry Draper Extension, 2. A series of thirtysix photographic sequences in and near Cygnus, based on the North Polar Sequence and obtained by means of plates taken with the 3-inch Ross lens. Unpublished. Measurements and reductions by Mrs Gaposchkin.

6. Photographic Magnitudes in the Selected Areas South of and Including the Equator. Programme, to obtain good photographic magnitudes for all stars for which spectra have been, or will be, classified by Becker. The zone at $-15^{\circ}$ has been completed (as spectra are not yet published for this zone, all stars given in the Harvard-Groningen Durchmusterung at this declination, down to magnitude 13.00 , have been measured). A comparison with the Mount Wilson magnitudes shows satisfactory accordance; the magnitudes will be discussed with those of the Harvard-Groningen Durchmusterung, and will provide corrections for that system when the colours and spectra of the stars are available (see following paragraph). The plates are taken with the 8-inch Bache telescope, in series with the Harvard Standard Regions. A subsidiary investigation is in progress: (a) redetermination of the relation of the photographic magnitudes in the $\mathrm{C}\left(+15^{\circ}\right)$ Standard Regions to the North Polar Sequence, with special reference to zero point; $(b)$ intercomparison of all Standard Regions with reference to zero point and scale.

7. Red Magnitudes in Southern Selected Areas. By comparison with the newly determined red standards, magnitudes are to be determined on red plates for all stars included in Programme (6), thus providing material for a discussion of brightness, colour, and spectrum, for a number of stars down to the thirteenth magnitude. Measurement and reduction are in progress for the Areas at $-15^{\circ}$, on the basis of plates taken with the I2-inch (MA) Metcalf refractor, emulsion I-C Special, Cine Red filter. Plates for more southerly Selected Areas are to be taken with the 24-inch Bruce refractor, using the same plate-and-filter combination. The magnitude scale is in all cases checked by means of a continuously calibrated objective grating.

8. Determination of Red Standards. Red magnitudes, made with plates of emulsion type I-C Special and a Cine Red filter, have been determined at the North Polar Sequence, and in the Harvard Standard Regions (C) at $+15^{\circ}$, using a continuously calibrated objective grating of aluminium in conjunction with the 12 -inch (MA) Metcalf refractor. The zero point of the system is set by making the blueyellow colbur indices of stars of the North Polar Sequence equal to zero for the same stars for which the blue-red colour indices are zero. (In practice the zero point is determined by assuming a linear correlation between blue-yellow and blue-red 
colour indices, as the observed deviations from linearity are negligible.) The magnitudes have been carried to $14^{\mathrm{m} \cdot} \cdot 0(\mathrm{pg})$. For programmes (6), (7) and (8), measurements by Mr Gaposchkin; reductions by him and Mrs Gaposchkin.

9. Magnitudes in Harvard Standard Regions. In the sixteen square degrees surrounding each of the Standard Regions it is planned to obtain the magnitudes of all stars in the photographic, photovisual, and red systems and to discuss the resulting material on star colours with reference to the observed spectra. The thirteenth magnitude $(\mathrm{pg})$ has been selected for the limit in this investigation. The photovisual magnitudes are largely measured and reduced; the red magnitudes are in progress. The photographic magnitudes are postponed until the colour coefficients of the instruments involved are better determined than at present. Student assistants, with aid from Mrs Gaposchkin. Some unpublished work by Miss Leavitt and her assistants is being used.

ro. Colour Coefficients of Photographic Systems. Direct determinations of the colour coefficients of the magnitude systems given by focal plates taken with the 24-inch Bruce, the I6-inch Metcalf (both before and after refiguring), the I2-inch Metcalf, the Io-inch Metcalf, the 8-inch Draper, and the 3-inch Ross lenses have been made. In general they depend upon both colour and brightness. Mrs Gaposchkin, and students.

II. Photovisual Standards for Variable Stars. Material has been collected, by direct polar comparison with the I2-inch Metcalf telescope, for the determination of photovisual standards for about forty well-known variable stars. The method will be precisely the same as for Investigation (3). At present there is no immediate prospect of measuring and reducing these plates.

I2. Red Standards for Variable Stars. As an experiment in visual observing, seven red-magnitude sequences have been determined photographically for bright red variables, which will be used by visual observers with a Ciné Red screen similar to that used in taking the standard plates. The sequences are based on those of Investigation (8). They are not published. Measurements by Mr Gaposchkin; reductions by him and Mrs Gaposchkin.

Cecilia Payne Gaposchin

r. Dr W. A. Calder and his assistant, Mr John W. Evans, have inaugurated an extended programme on photo-electric magnitudes of stars to the eleventh magnitude. The work will be carried on for the present only in the North Polar Sequence and in the Pleiades, but within the next few weeks it will be in systematic operation for the brighter stars in the Harvard Standard Regions and in the northern Selected Areas. Two different photo-electric photometers will be involved in this work, one working directly with photo cell and Lindemann electrometer and the other with an amplification system. The telescopes used are the 24-inch Clark reflector and the 6o-inch Wyeth reflector at the Oak Ridge Station. The accuracy obtained is that usual for the best photo-electricmagnitude work. Kunz potassium photo-cells are the only ones in use at present; their energy distribution as measured gives magnitudes nearly identical with the international photographic magnitude scale. It is hoped that a finished report on the photo-electric magnitude differences for the brighter stars of the North Polar Sequence can be presented at the Paris meeting.

2. A type of photometric work carried on very extensively in the nebular department and in the variable star department of the Observatory may be mentioned, namely, the use of star-counting methods and the tables of Seares and van Rhijn 
for the establishment of magnitude sequences in the higher galactic latitudes. On all of our long exposure programmes (three-hour exposures) with the Bruce 24-inch telescope and with the Metcalf I6-inch telescope at Bloemfontein and Oak Ridge, respectively, we are setting up magnitude sequences that extend from approximately the fourteenth to the eighteenth magnitude. Sequences are established through star counts over two square degrees on each plate. The counting is sufficiently accurate, whether to the limit of the plate or to specified brighter magnitudes, we have been able to show, to set up sequences as dependable as the tables on which they are based will permit. We find that when it is possible to compare our new sequences of stellar magnitudes with neighbouring Selected Area sequences, the agreement is satisfactory, at least to magnitude $\mathrm{r} 7 \cdot 5$. The method is particularly useful to us in the study of variable stars and of the distribution of external galaxies. About roo sequences have been determined by this method for the nebular surveys at present; fifty more will be determined during the coming winter. We do not attempt the establishment of sequences by this method for galactic latitudes less than plus or minus 20 degrees.

3. Mr Seyfert, of the Observatory, is working on the determination by extra-focal methods of the total magnitudes of a considerable number of the external galaxies between magnitudes ten and thirteen listed in Harvard Annals, 88, No. 2. The photographic plates are measured with a densitometer. Mr Seyfert is not quite in a position to make a statement concerning his results.

HaRLOW SHaPLEY

\section{Observatoire Royal de Belgigue,}

During this last term has appeared my investigation: Etude de l'amas de Praesepe, basée sur les magnitudes photographiques et les longueurs d'onde effectives de I82I étoiles. Gembloux, J. Duculet, r933.

The effective wave-lengths are deduced from 52 plates taken with the 60-inch reflector of Mt Wilson Observatory and covering a region of $2^{\circ} .5$ in diameter. The photographic magnitudes are measured on 6 plates taken with the I2-inch Zeiss triplet of the Uccle Observatory, and based on Hertzsprung's system of magnitudes of 308 stars in Praesepe (A.N. 205, 5I, I9I7).

This investigation is divided into three parts: (I) a detailed indication of the methods of observation and discussion; (2) comparisons between our system of effective wave-lengths and other systems of colour equivalents, namely the colour indices of 36 stars in the Polar Sequence, the colour indices of 35 stars of the Gottingen Actinometry, the effective wave-lengths of 58 Praesepe stars determined by Hertzsprung, and the colour indices of 55 Praesepe stars by van den Bos; (3) the discussion of the catalogue data of 1821 stars in the Praesepe region, namely, the deduction of the relations between $(a)$ the proper motions and the magnitudes; (b) the proper motions, the magnitudes, and the effective wave-lengths; $(c)$ the effective wave-lengths and the photographic magnitudes, respectively, for cluster and non-cluster stars to the fifteenth magnitude; $(d)$ the effective wave-lengths and the spectral types for the physical members to the eleventh magnitude. The parallax of the cluster derived from the discussion of these physical data is 0 ".007.

The General Catalogue of I82I stars includes the coordinates for I925.0, the proper motions derived by Klein Wassink (Gron. Publ. No. 4I), the photographic magnitudes, the effective wave-lengths and their relative weight, and the distance of each star from the centre of the cluster. 
A similar investigation based on the effective wave-lengths and the photographic magnitudes of II50 stars in Messier 67 is almost ready for publication.

I have also started the measurement of the effective wave-lengths of about 300 condensations in the spiral arms of the spiral nebula Messier 5I.

\section{H. L. VANDERLINDEN}

\section{KAPTEYN ASTRONOMical LABORATORY}

The photographic magnitudes of stars brighter than $I_{3}$ in the northern Selected Areas I to II5 are being determined at the Kapteyn Laboratory, Groningen, with a Schilt microphotometer on plates taken with the 8-inch Draper lens of the Harvard Observatory $\left(I^{\prime}=0.367 \mathrm{~mm}\right.$.). The spectral classes of the stars are being determined at the Hamburger Sternwarte by Prof. Schwassmann. The field of each Selected Area is $3^{\circ} \cdot 5 \times 3^{\circ} \cdot 5$. The magnitudes of Areas I to 7 are finished and will be published shortly, together with the spectral classes. The standard magnitudes of each Area have been found by means of 5 to 7 polar comparison plates, using as a basis the international magnitudes of the polar stars. It appears that the colour equation of the magnitudes relative to the International System is practically zero. Further, since the scale and zero point agree with the Mount Wilson Catalogue of Photographic Magnitudes in Selected Areas I to I39, the magnitudes are on the International System.

P. J. VAN RHIJN

\section{Mount Wilson Observatory, Carnegie Institution of Washington}

I. An extension of the photographic scale to magnitude 20.5 in Selected Areas 51 , $57,6 \mathrm{r}, 68,73$, and 89 is well under way. The results will supply faint standards of magnitude in fields accessible to the Ioo-inch reflector, which cannot be directed to the polar region, and make it possible to avoid the risk of the residual rotation of field which is likely to affect long exposures on the pole. Although the choice of the Areas has been determined mainly by the needs of current photometric research on nebulae, the zone $+15^{\circ}$ to $+30^{\circ}$ of declination is satisfactorily covered. The programme includes for each field $(a)$ three 6o-inch reflector plates, two exposures of I hour each with full aperture and 32-inch diaphragm; interval covered, $17 \cdot 0$ to I9.4; (b) three Ioo-inch reflector photographs, exposures $I$ hour with 85 - and 58 -inch diaphragms, interval $17 \cdot 0$ to 20.4 . Zero points are based on the Mount Wilson Catalogue. All the 6o-inch plates and half of those with the roo-inch reflector have been obtained. Complete reductions for two Areas show, in spite of the long exposures, a very satisfactory internal accordance in the individual magnitudes.

W. BAADE

2. The plan for the extension of the list of polar standard magnitudes, which in its earlier stages was concerned with the systematic corrections to the existing catalogues (Trans. I.A.U. 4, I45, I932), has been extended to include special measurements of the photographic and photovisual magnitudes of about 2000 stars in declinations $+80^{\circ}$ to $+90^{\circ}$ between photographic limits of about $5^{\circ} \mathrm{O}$ and II.5 to 12.0 . 
The reasons for including so many stars are as follows: Stars to the limit specified will frequently be observed with large-field cameras. With a 5-inch lens designed by F. E. Ross, we are obtaining magnitudes of excellent precision over a field $\mathrm{II}^{\circ}$ to $12^{\circ}$ in diameter. The plate corrections depend on size of image, and, for many instruments, on position angle, as well as distance from the optical axis. Moreover, these corrections may vary somewhat from plate to plate, especially in the outer zones of the field. Colour corrections also frequently depend on size of image. To determine all these corrections satisfactorily numerous standards are required; with the full field of the Ross lens it often happens that 200 per field are none too many. Finally, comparisons depending on exposures centred on the Pole itself, unless very short, are likely to be affected by systematic errors arising from defective polar images. A polar distance of $3^{\circ}$ to $4^{\circ}$ seems to give satisfactory results. The lower limit of declination accordingly was fixed at $+80^{\circ}$.

The scale and colour system are those of the International Polar Sequence (Trans. I.A.U. I, 71, 1922). The standard values will be weighted means, with a precision in most cases comparable with that of the P.S. standards themselves and will include (a) magnitudes from existing catalogues, reduced to the standard system with the aid of systematic corrections first presented to the Commission at the 1932 meeting and since revised and published in $M t W i l s o n$ Contr., Nos. 472, 489; $A p . J$. 78, I4I, I933, 79, 203, I934; (b) magnitudes determined jointly with Dr F. E. Ross of the Yerkes Observatory. Certain observational details have already been given in the publications just cited. Additional details and tests of precision will be presented in connection with the results themselves.

The magnitudes from (a) are complete. The photographic magnitudes from $(b)$ are also complete, except that small corrections for colour amounting to 0.01 or 0.02 mag. may still be required, owing to the fact that the colour indices are provisional and for most of the faint stars still uncertain. The observations and measurements for the photovisual magnitudes are finished.

\author{
F. H. SEARES \\ President of the Commission
}

March 9, I935 